\title{
Noore Ain Kaalepi kirjad Marta Sillaotsale Nõmmele Valguse tänavale
}

\section{Katiliina Gielen}

Eesti Kirjandusmuuseumi kultuuriloolises arhiivis on hoiul pakk 20-aastase Ain Kaalepi kirju tädi Martale Nõmmele Valguse tänavale1. Need 1946.-1947. aastal kirjutatud ja osaliselt illustreeritud 16 kirja ning kimp luuletusi on muuseumi jõudnud Marta Sillaotsa 1961. aastal tehtud annetuse kaudu. Kirjad sisaldavad mahlakat materjali just tulevastele Kaalepi uurijatele, lubades samas teha järeldusi ka Sillaotsa tolleaegse positsiooni kohta eesti kirjandusilmas.

Tõlkija, kirjanduskriitik ja romaanikirjanik Marta Sillaots (1887-1969) töötas kuni arreteerimiseni 21. detsembril 1950. aastal vabakutselise tõlkijana. Eesti Vabariigi ajal prantsuse ja saksa autorite vahendamisega leiba teeninud Sillaots tegeles pärast 1940. aasta riigipööret põhiliselt vene autorite loomingu (peamiselt näitekirjanduse) või siis Lääne autorite tõlkimisega vene keele vahendusel. 2 Meeldivaks vahelduseks venekeelsetele näidenditele oli Charles Dickensi „Pickwick-klubi järelejäänud paberite“ tõlkimine otse inglise keelest.

Ain Kaalep (snd 1926) oli lõpetanud 1943. aastal Hugo Treffneri Gümnaasiumi, sama aasta sügisel astunud Tartu ülikooli õppima soome-ugri keeli, kuid kuu aega pärast immatrikulatsiooni põgenenud Soome, kus astus armeesse. Tagasi Eestisse jõudis soomepoiss ${ }^{3}$ Kaalep 1944. aasta hilissuvel. Õpinguid ülikoolis õnnestus tal jätkata kuni 1945. aasta veebruarini, seejärel tuli arreteerimine ja 13 kuud Patarei vanglat. Sillaotsaga kirjavahetusse astudes oli äsja amnesteeritud noor Kaalep õppimas ülikoolis soome-ugri keeli, selle kõrval siiski romaani keeltega sidemeid säilitades ja edasi arendades, „kui mitte muuks, siis lugemaks France'i ja Rolland'i originaalis“ (EKLA, f 243, m 1: 2, I 1/2).

Noore, laia silmaringi ja tärkava keelehuviga Kaalepi piiritu, tihtipeale eneseirooniaga vürtsitatud austus Sillaotsa vastu väljendub juba esimese kirja (11. juunil 1946) sissejuhatuses, kus Kaalep oma pikka vaikimist põhjendab:

Enne kõike tunnen end väga süüdlasena selles, et ma nii kaua viivitasin selle kirjaga. Pääpõhjuseks oli muidugi kartlik respekt, mida tunnen inimeste ees, kellede autoriteeti tunnustan. Omavahel öeldud: see teatud arglikus pole praegugi kadunud. Tunnen kogu

1 Marta Sillaots elas Nõmmel Valguse tänav 19.

2 Näiteks tõlkis Sillaots 1945. aastal vene keele vahendusel John Boynton Priestley näidendi „Ta tuli“, aga ka mitmeid vene autorite näidendeid, näiteks Aleksandr Afinogenovi „Mašake“, Jevgeni Švartsi „Vari“, Boriss Lavrenjovi „Murrang“.

3 Soomepoisid olid 1939-1945 Soome armees vabatahtlikena teeninud Eesti mehed. 
aja hirmu, et mõni naeruväärsus neil poognail Teieni jõuab; võib-olla kuulub selliste hulka juba seesama pihtiv algus?

(EKLA, f 243, m 1: 2, I 1/1.)

Kuigi Ain Kaalep tundis literaat Marta Sillaotsa tema tööde vahendusel ammu enne isiklikku kokkupuudet ${ }^{4}$, algas Sillaotsa tutvus Ain Kaalepiga 1946. aasta hilissügisel Kaalepi kursusekaaslase Evi Puskari kaudu. ${ }^{5}$ Puskarist, kes oli Sillaotsa osavõtul tegutsenud Nõmme X Keskkooli (Nõmme Gümnaasium) humanitaarringi ${ }^{6}$ sekretär (Kahk 1994: 51), sai 1946. aastal ühenduslüli Tartu ja Tallinna (Nõmme) kirjandushuviliste noorte vahel. Sillaots on tugevasti mõjutanud paljusid kultuurihuvilisi noori, kes temaga kokku puutusid, Ain Kaalepit teiste hulgas. Humanitaarringist kasvas välja oluline sõpruskond: Vidrik Kivilo (tegutses ka Sillaotsa erasekretärina), Kulno Süvalepp, Eino Tamberg, Juhan Kahk, Naata Raudsep, Valmen Hallap, Aime Õngo, Leili-Maria Kask ja mitmed teised hilisemad tuntud kultuuritegelased. Koos käidi mitmeid kordi kuus, loeti raamatuid ja arutleti kirjanduse üle, musitseeriti, luuletati ja valmistati ette operett ${ }^{7}$, viimast küll enne Kaalepi liitumist Sillaotsa sõpruskonnaga.

Esimeste kirjade ajendiks ja ka üldiselt kirjavahetust läbivaks teemaks on Kaalepi luulekatsetused, mida ta esmalt Puskari õhutusel ja siis juba Sillaotsa enda palvel kogenud kirjandusarvustajale lugeda saatis. Sillaotsa huvi noorte luuletajate vastu on mõnevõrra üllatav, sest vaatamata nooruspõlve katsetustele ja mõnele avaldatud värsile ${ }^{8}$ ei puuduta Sillaots oma kirjandusarvustustes ${ }^{9}$ kunagi luulet. Ka 1935. aastast pärinevas vastuses Eesti Kirjanduse toonase peatoimetaja Daniel Palgi pakkumisele kirjutada arvustus Ferdinand Karlsoni sonetikogule „Rännakuil“ teatab Sillaots, et luuletuste vallas ei pea ta end kompetentseks ja seepärast luulet arvustada ei võta (EKLA, f 257, $m$ 3: 6, I 3/3). Teisalt on Sillaotsa alati huvitanud noored ja noorsookirjandus, mille tähtsust Kaalepi sõnul „ükski kirjandus-

4 Ühes esimeses, 11. novembrist 1946 pärinevas kirjas ütleb Ain Kaalep end olevat Sillaotsaga kohtunud Anatole France'i ja Romain Rolland'i tõlgete kaudu (vt EKLA, f 243, m 1: 2).

5 Kohtumisi Marta Sillaotsaga kirjeldab Ain Kaalep „Kollase toa saladuses“, esmakordselt ilmunud 1989. aasta kirjanduse ülevaates „Kirjanduse jaosmaa '87“, aga ka Eesti mõtteloo sarjas („Kolm Lydiat“, 1997).

6 Sillaotsa kutsus 1945. aastal Nõmme X Keskkooli juures tegutsenud humanitaarringi koosolekule Vidrik Kivilo, kelle tutvus Sillaotsaga oli alanud juba 1944. aastal. Sillaotsast sai populaarseks kujunenud kirjandusvõistluste žürii esinaine, võistlusele laekunud töid vaeti Sillaotsa kodus Valguse tänaval (vt Kahk 1994: 52).

7 Operett „Odysseus” kanti ette kooli aastapäeval 1945. aastal (vt Kahk 1994: 60).

8 Mõni Sillaotsa luuletus on ilmunud perioodikas, näiteks „Noored põllumehed“ (Kiir, 4. mai 1917), „Minu mõrsjale“ (Kosjaleht, 1919, nr 4, Ik 23).

9 Sillaotsa kirjandusarvustusi ilmus alates 1912. aastast, eriti rohkesti 1920/1930. aastatel ajakirjades Eesti Kirjandus ja Looming, aga ka mujal perioodikas. 
ajaloolane oma tolmunud ajudega veel pole vääriliselt hinnanud“ (EKLA, f 243, m 1: 2, | 4/13). Kaalepilt kirjavahetuse käigus Sillaotsale saadetud 30 luuletuse hulgas on mitmeid, mis on hiljem avaldatud. ${ }^{10}$ Luuletus pealkirjaga „Grüps“ on saadetud Sillaotsa 60. sünnipäeva puhul koos pidulike õnnitluste ja luuletuse tausta seletava kirjaga.

Üldiselt paistab Kaalepi kirjadest Sillaotsa soosiv suhtumine ja heatahtlik huvi noore haritlase vastu. Ilmselt võlus Sillaotsa Kaalepi kirjade vaba ja siiras mõttevool ning mitte just ülemääraselt tõsine stiil. Sillaotsa palvel kirjutab Kaalep oma senisest elust, mis „hõlmab esialgu vaid 20 aastat, mille jooksul on möödunud kirev, kuid päikseline lapsepõli, võrdlemisi äge nooruse algus ja tähendusrikkad sõjapäevad süngete komplikatsioonidega" (samas, I 1/1). Kirjanduslike katsetuste algust kirjeldab Kaalep talle omase humoorikusega:

Kirjanduslikke nõrkusi on mu juurest avastatud juba 4-dast eluaastast, mil lugema hakkasin - nii lugejana kui "loojana“. 9-aastaselt kirjutasin võimsa raamatu "Minu elu“. 12-aastaselt sain maha värssdraamaga "Madame Dubarry“ (veel uhkem saavutus oli luuletus „Ma süüdistan“, kus näha võis umbes taolisi värsse:

Tõmblev mass, üksikud liikmed.

Punakas kuma.

Öö.

Kuskil on Tema.

Kus? Jne.)

(Samas, I 1/2-1/3.)

Sillaotsa pool koosviibimistel käinud Nõmme Gümnaasiumi humanitaarringi kirjandussektsiooni õpilastest mainitakse kirjades enim Vidrik Kivilod, keda Kaalep pärast külaskäiku Valguse tänavale alatasa tervitada laseb ja keda koos Sillaotsaga Tartusse visiteerima kutsub. Kivilo on ka esimene, kes Marta Sillaotsa mitmekülgse elutöö iseloomustamiseks kasutab terminit „literaat“ (vt Kivilo 1969: 1279). Kaalepi sagedased küllakutsed moodustavad kirju läbiva teema, võttes vahel käskiv-kamandava ja vahel iroonilise alatooni: „Tahan ainult, et teie Vidrikuga väisaksite mind mu apartemangus, ja et te oleksite Tartus vähemalt kolm nädalat. Tahan, et see hästi ruttu toimuks. (Vabandust muidugi veltveeblitooni pärast.)“ (EKLA, f 243, m 1: 2, I 6/18.) Või teisal: „Tartu pole linn ega midagi. Vähemalt näivad seda rumalavõitu seisukohta omavat teatavad inimesed, kes aeg-ajalt lubavad siia sõita, tegelikult aga vist ei mõtlegi. Grr!" (Samas, I 14/46.) Pärast mitmeid tulutuid katseid Sillaotsa ja Kivilod Tartusse meelitada saadab Kaalep Sillaotsale 4. novembril 1947. aastal kaardikese luuletusega, milles sisaldub ka tsitaat 1935. aastal esmakordselt ja 1946. aastal kordustrü-

10 Näiteks kogus „Klaasmaastikud“ (1971) ilmusid 1946. aastal kirjutatud ja Sillaotsale lugemiseks saadetud „Kratt”, „Nuganna-Grulla“ ja „Kurat“. 
kina ilmunud Sillaotsa tõlgitud „Colas Breugnonist“ (alapealkirjaga „Elame veel!“, mis kujunes 1940. aastate lõpus rahva seas populaarseks hüüdlauseks):

Oh proua Sillaots, ma olen laisaks läinud.

Kas on ehk mu esprii hoopis maha nüüd käinud

või päikeseplekkidest tuleb leida see jõud, see, mille tagajärg minu ajus on põud...

Võibolla juba Te mind lillaks laibaks peate ümber lükkamaks see saadan väikese teate: ega umbrohi kao, ja: ME ELAME VEEL. Kuid hoopis rõõmsam küll oleks tartlaste meel, kui kohtaksime Teid Tartu jaama perroonil ja seda üsna pea, veel osalt suve foonil. Te tulete ju, eks? Ja kuidas, lähemalt? Või muidu nutab siin Ain Kaalep vähemalt.

1.9.47

(Samas, I 12/41.)

Nagu selgub järgnevatest kirjadest, siis vaatamata kutsete rohkusele ja atraktiivsusele Sillaots 1947. aasta sügisel Tartusse ikkagi ei jõudnud.

Aastatel 1946-1947 oli Sillaots ametis Charles Dickensi „Pickwick-klubi järelejäänud paberite" esimese osa tõlkimisega (ilmus 1948). Sellest tegevusest said osa ka Sillaotsa noored saatevaimud, ikka Nõmme humanitaarringiga seotud inimesed, ka mõned tartlased eesotsas Ain Kaalepiga. Kaalep kirjeldab „Kollase toa saladuses“ oma osalust tõlkekäsikirja valmimises: „Muide on minu soovitusel Sam Welleri sõnavarasse sattunud sõna „ülesseleiutis“ - enne oli lihtsalt „väljamõeldis““ (Kaalep 1997: 541). Kirjades puuduvad peaaegu täielikult vihjed maailmas toimuvatele muutustele või rasketele aegadele.

Avaldamiseks on valitud noore Ain Kaalepi neljas kiri Marta Sillaotsale 29. detsembrist 1946 (EKLA, f 243, m 1: 2, I 4/12-4/14). Alljärgnev kiri on tore tagasivaade tänavu oma 86. sünnipäeva tähistanud Ain Kaalepi kujunemistee algusesse. 
Lp. pr. Sillaots.

Täna kirjutan mina ka pliiatsiga, kuna mu pisike tragi õde (14) ${ }^{11}$ on koristades tuba kõik sulepääd pannud kohtadesse, kust neid lähema kümne aasta jooksul pole lootust leida.

Kõige päält on mul kangesti kahju, et meie vestlusel nüüd nii pikk vahe oli. Ma nimelt vahepääl võtsin kogu aja hoogu õppimiseks, ${ }^{12}$ nüüd aga, mil tõesti juba õppima peaks, jätsin selle mõtte hoopis katki päästmaks olukorda viimasel hetkel öid koffeiini abil abiks võttes. Sinna on veel aega.

Tallinnasse - Nõmmele saab kahtlemata tuldud. Sõpradest olid mitmed plaaniga nõus; Juta Annusega ${ }^{13}$ pole ma veel sel teemal kõnelnud. See tuleb kõne alla jaanuari lõpul. Vähemalt enda puhul võin küll öelda, et kui ma vahepeal auto alla ei jää või midagi analoogiliselt koledat ei juhtu, saan ma tulema.

Küsite minult igasuguseid küsimusi, millele nüüd järjekorras vastama hakkan kangesti piinlikkust tundes, et pean kogu aja esimest isikut tarvitama.

Helgi R. ${ }^{14}$ luuletused on minu arvates selles mõttes väärtuslikud, et nad on väga ehtsad. Sõbrana lugedes pakuvad nad arvatavasti rohkem, kuna autor ja ta iseloom on kogu aja silme ees. Luuletustena iseendas (an sich) nad võib-olla ei paku nii palju. Kuid igal juhul ma ei jaga nende seisukohti, kes arvavad, et Laps (s.o. H.R) jääb alati selliseks, et tema puhul võib ikka öelda: temast saab asja. Arvan päris tõsiselt, et temast saabki. Nii mõnigi ta värss meeldib mulle kangesti, kuigi juba nende laad, mis on suuresti vastuolus minu omaga, mulle ikkagi jääb veidi võõraks.

Muide kardan arvustada, kuigi seda meeldib mulle teha.

Suitsetan, ja alkohoolsed joogid pole mulle eriti antipaatsed, välja-arvatud igasugused kleepivad ja magusad.

Ühiskondlikud probleemid on mu vana ja näib, et õnnetu armastus. Jäin nendega tegelemises poolele teele; hea algus ei leidnud olude sunnil edasiarendamist. Nüüd olen jõudnud nii kaugele, et isegi ajalugu (teadusena) mind enam ei huvita. Üldse on imelik kirjutada midagi sellist; neil teemadel vestelda on võõras ja natuke valus. Sest lõpuks selgub,

11 Ain Kaalepi õde Tiiu, keda kirjades sagedasti mainitakse.

12 Kaalep õppis 1946. aastal Tartu ülikoolis soome-ugri keeli (Iõpetas 1956), täiendades ennast pidevalt eriti romaani keelte alal.

13 Juta Annus (Erma) tutvus Kaalepiga 1946. aastal Evi Puskari kaudu; koos Kalju Kanguri ja Juta Annusega tehti esimene visiit Sillaotsa kirjandusringi Nõmmel (vt Kaalep 1997: 540). Sissekanne Sillaotsa külalisraamatusse „Tahan olla kangesti alandlik. Ain Kaalep“ märgib külaskäigu kuupäevaks 26.01.1947 (EKLA, f 243, m 6: 1, I 84).

14 Helgi Reidak, hiljem Helgi Kauber. 
et polegi millest huvituda. Kunstid? Kuid siingi muutub meel nukraks tundes võimetust leida baasi oma pürgimustele vaid neis; ei suuda lihtsalt induda öötuule haardest. Beethoveni vaimustav jõud, Mozarti sügav elurõõm, Bachi võimukas vagadus võivad viia vaid meeleheitele. Tšaikovski nukker ilu võiks sundida nutma.

Selle ähmaselt traagilise repliigiga olen ühtlasi vastanud ka Teie küsimusele minu muusikalistest huvidest ning ära toonud oma lemmikkomponistid. Muide Wagnerit ja Itaalia veriste ma ei salli. Kas Te suudate mõista, miks sümpaatsele onu Shaw'le meeldis Wagner? Ka Rolland teeb temast kuskil päris ülistavalt juttu. Seda aga arvan kuidagi mõistvat.

Suits meeldis mulle 4 aastat tagasi. Nüüd arvan, et teda on üsnagi kõvasti üle määra ülistatud. Mis aga puutub Eesti kirjandusse üldse, siis pean meie tippteoseiks „Mäeküla piimameest“; „T ja Õ“; „Põrgupõhjat“ ja „Väikest Illimari“15 proosa alal. Luulest meeldis väga Marie Under, keda ma ei väsinud ülistamast ja „absoluutse väärtuslikkuse“ seisukohast asetamast kõrgemale Tammsaarest. Nüüd aga on ta mulle kuidagi võõraks jäänud ja ma naudin täite sõõmudega Betti Alveri sädelevaid ridu. Ka Uku Masing ning Heiti Talvik on mulle väga meele järele. Parimaks Eesti draamateoseks pean „Vedelvorsti“16. Ja arvan, et kõneldes eesti kirjandusest ei tohi kunagi jätta tähele panemata Ristikivi tõusvat suurvaimu. Noorsookirjanduses (mille tähtsust ükski kirjandusajaloolane oma tolmunud ajudega veel pole vääriliselt hinnanud) on meil olemas „Kevade“ ja Trips-Traps-Trulli lood ${ }^{17}$.

Mul on väga kahju, et ma ei oska vene keelt jagamaks muljeid, mida saate Teie selle huvitava vene poeedi loomingust ${ }^{18}$. Tõtt-öelda ma ei oska, hoolimata lähenevast arvestusest, siiamaani ühtki sõna lõpuni käänata.

Samuti on mul kahju, et ma pole lugenud „Pickwicki“"19, kuid arvan, et see teos mulle kangesti meeldima saab, ning rõõmutsen kuuldes selle tõlke valmimisest. Dickens on minu arvates üks sümpaatsemaid vanu onusid ja mind tabab alati otse kohkunud üllatus, kui leian inimesi, kellele ei meeldi David Copperfield. Mul on kahju, et mu inglise keel on puudulik ja tunnen süümepiinu mõeldes sellele, et ma pole vaevaks võtnud teda edasi arendada. Kuid

15 Eduard Vilde „Mäeküla piimamees“ (1916), A. H. Tammsaare „Tõde ja õigus“ (1926-1933) ja „Põrgupõhja uus vanapagan“ (1939), Friedebert Tuglase „Väike Illimar“ (1937).

16 Hugo Raudsepa näidend „Vedelvorst“ (1932).

17 Populaarne neljast raamatust koosnev lastejuttude sari (1935-1937), autor Marta Sillaots.

18 Mõeldud on ilmselt Vladimir Majakovskit.

19 „Pickwick-klubi järelejäänud paberite“ (1948) esimese köite tõlkimine lõpetati Sillaotsa külalisraamatu andmeil 1. veebruaril 1947. 
sellega on ju veel aega. Kuigi Huxleyd ja Lawrence'i (miks mitte ka Joyce'i) ${ }^{20}$ oleks väga tarvilik lugeda mitte olemaks euroopa kultuuri saavutuste tundmises 40 aastat taga.

Selle eest aga näen end vaimusilmade ees aasta pärast lugevat prantslasi, mis on veelgi tähtsam; vähemalt huvitavam.

Muide olen sulge murdnud ka tõlkimaga igasuguseid asju keeltest, mille oskamises ma kasvõi ainult esimese sammu olen astunud. (Gruusia luulega ma siiski hakkama ei saanud! ${ }^{21}$ ) Saadan teile vahest mõningad tõlked täna näha. Üldse lisan ma ühte ja teist; luuletuse, mille ma kohe valmimise järele Teile saatsin oma parima luuletuse nime all, ristisin ma "Toimuv“. Muide olen ma oma endistest luuletustest kõvasti tüdinud, sp näib mulle, et kõiki oma asju Teile saata oleks vist ülejõu. Ega nad pole kah midagi huvitavat. Ja praegu saadan Teile eeskätt mõned uusimad.

Kell on praegu umbes kahe ligi; näib, et uni juba mõtteselgust kahjustama hakkab, niisiis Iõpetan rohkete tervitustega.

Ain Kaalep

29.12.46.

\section{Ki r ja n d u s}

Kaalep, Ain 1997 [1989]. Kollase toa saladus. - Kolm Lydiat. Toim L. Tormis, A. Merilai, A. Kaalep. Tartu: IImamaa, Ik 537-543.

Kahk, Juhan 1994. Nõmme Gümnaasiumi (X Keskkooli) ajalugu I: 1929-1944. [Tallinn:] Nõmme Gümnaasium.

Kivilo, Vidrik 1969. Marta Sillaotsa mälestuseks. - Looming, nr 8, Ik 1279.

\section{Käsikirjalised a I I ikad}

Ain Kaalep, kuusteist kirja Marta Sillaotsale. 11. XI 1946 - 22. XI 1948. - EKLA, f 243, m 1: 2.

Marta Sillaots, kaheksateist kirja Daniel Palgile. 5. I 1935 - 29. X 1943. - EKLA, f 257, m 3: 6.

Marta Sillaots-Reichenbach-Rannati kogu. Varia. 2. XII 1944 - 2. IV 1947. - EKLA, f 243, m 6: 1.

20 Aldous Huxley, D. H. Lawrence, James Joyce.

21 Sillaotsa tõlkes ilmus 1947. aastal gruusia kirjaniku Leo Kiatšeli romaan „Gvadi Bigva“. Romaan on tôlgitud vene keelest. Üks Kaalepilt Sillaotsale saadetud luuletus kannab alapealkirja „Lugedes Dirri gruusia k. grammatikat“. IImselt proovis Kaalep kätt gruusia luule tõlkimisel Adolf Dirri „Theoretisch-praktische Grammatik der modernen georgischen (grusinischen) Sprache" (1904) abil. 


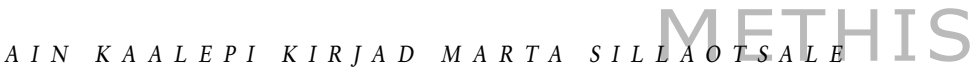

$4 / 2$

Sp. pr. Sillaots.

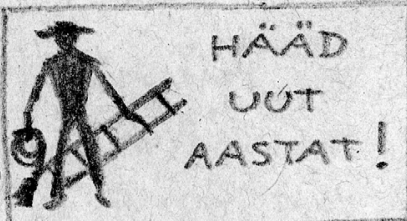

Täna kiyjutan mina ua plinatsiga, unna mu pisine tragi sde (14) on koristades tuba ko ine sulepääd pannul Kohtadesse, ment neid láhema kïmne casto joosmul pole lootust leida.

Körge paialet on mul kangert' Kah'n, et meie restensel minid nir pink vahe oli. Ma mimelt vahe. paial rötrin rogn aja hoogu ojy. misens, nüid aga, mie tóesti inta omima reaves, játrin selle mothe hoopis katri páästmans olure roha rimasel hetral oid coffeicini abve abies vóttes. Simna on veel aega.

Tallinnasse-Nómmele saab vahtlemata tuldid. Söpradest olid mitmed Nearaniga nóns; Juta Annusega pole ma reel sel teemal nonelnud? see tuleb wöne alla puanuari cópul. Vähemalt enda puhul vóm wïl öl. La, et kni ma vahepeal cuto alla i páa vori midagi analoogrexelt kolidat ei puhtu, saan ma tulema.

Ain Kaalepi kiri 29. dets 1946. aastal Marta Sillaotsale. EKLA, f 243, m 1: 2, I 1/1.

211 
METRH HITS $T_{E I D}$

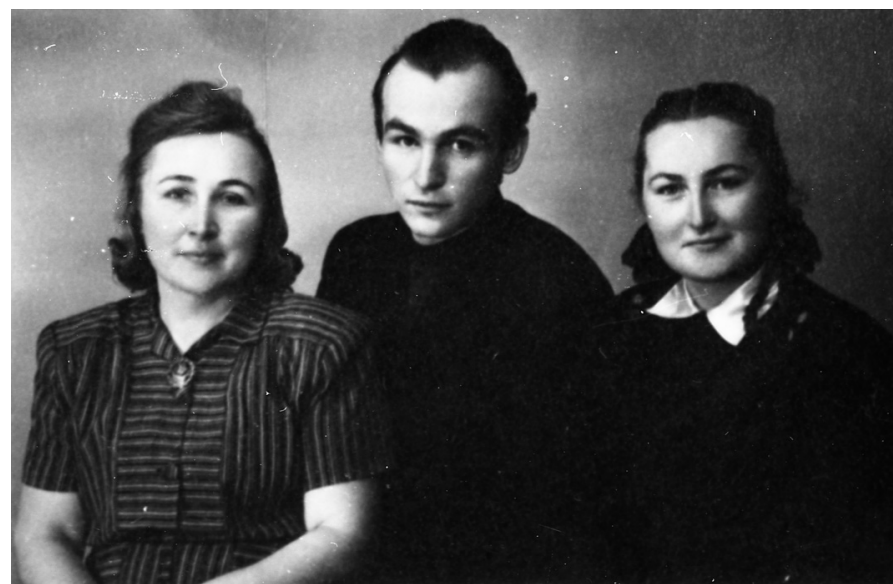

Ain Kaalep koos ema Magdaleena ja õde Tiiuga [1946]. EKLA, B-37: 7350.

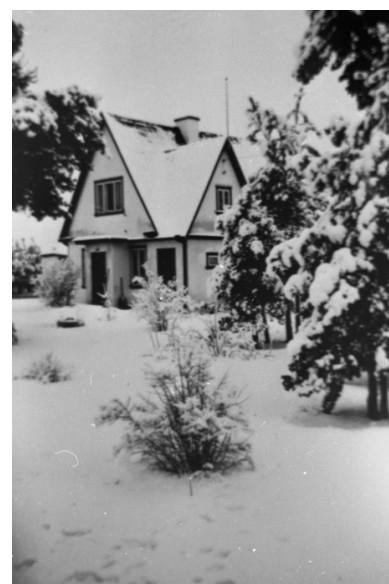

Marta Sillaotsa maja Tallinnas Nõmmel, Valguse 19. EKLA, A-116: 4

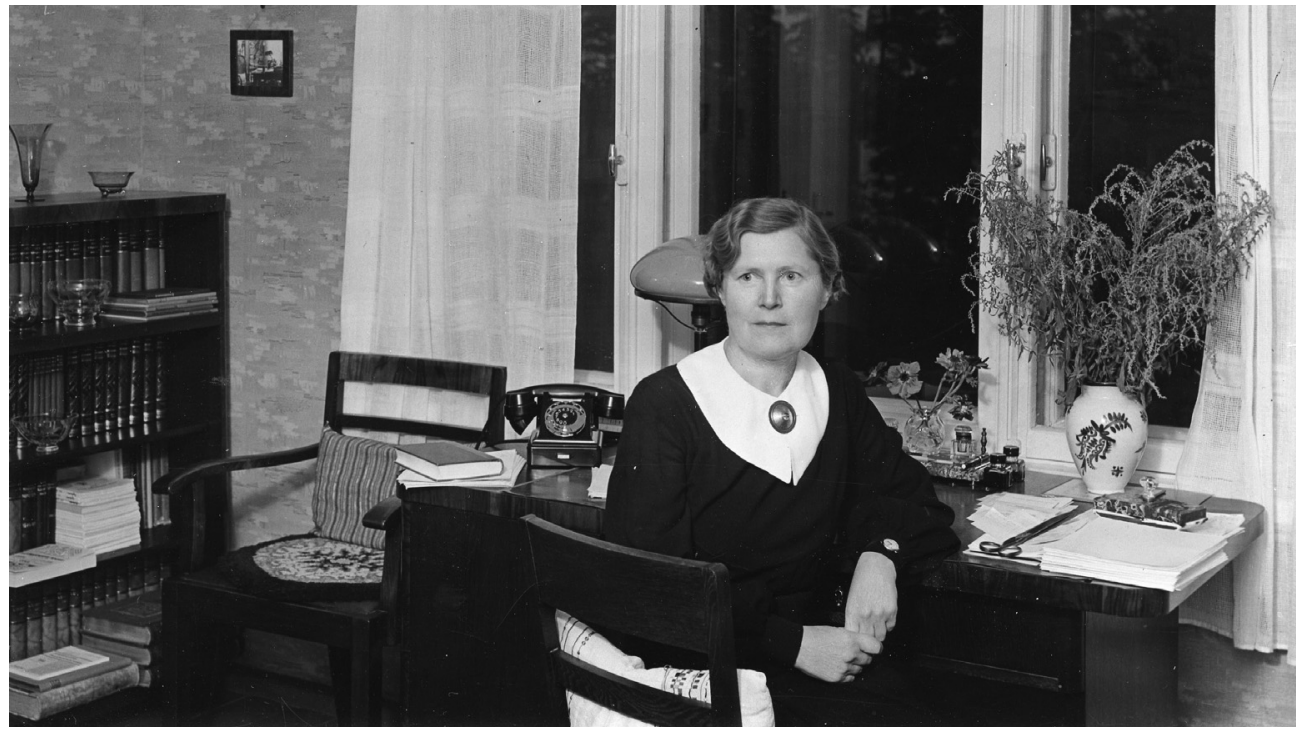

Marta Sillaots oma töötoas 1939. aastal. EKLA, B116: 2. 